\title{
INFORME SOBRE LOS MATERIALES DE ACATA EXISTENTE EN EL MUSEO DONADO POR EL DR. G. SCHROEDER \\ Félix Álvarez
}

El arqueólogo alemán Dr. G. Schroeder, hizo entrega al Museo de Arqueología y Etnología de la Universidad de San Marcos de un pequeño informe que acompañaba, en calidad de relación a un donativo que él mismo hizo a dicho museo, y que venía fechado en Arequipa a 5-4-1958. El donativo consistía en: "43 artefactos de piedra como ejemplares típicos de una cultura paleolítica del Perú y de 15 artefactos como material de enseñanza intuitiva en las clases de arqueología" (Schroeder, Breve informe manuscrito, 1958). En este informe el Dr. Schroeder hace una relación de los objetos que dona al Museo. La relación es breve y en ella describe 43 artefactos distinguiendo entre ellos, núcleos, raspadores, raederas, lascas y puntas. Estos artefactos provienen de una excavación en trinchera que hizo en setiembre de 1956 en los abrigos rocosos de Arcata (Par 5-1), en Castilla, departamento de Arequipa.

El Dr. Schroeder, según él mismo escribe (Revista del Museo Nacional, 1957) fue inducido por $\mathrm{O}$. Menghin a trabajar en el período Lítico, que era el menos conocido. Confiesa que los primeros momentos no tuvo suerte, “...pero en 1953 explorando las minas de la región de Ichuña encontró una cueva al lado del camino, pocos kilómetros antes de llegar al pueblo de Ichuña. La cueva no es completa sino más bien un refugio abierto" (Revista Museo Nacional, 1957, pág. 291). Este fue el pri- mer hallazgo del Dr. Schroeder, de donde, tras una excavación sistemática, consiguió unas 40 puntas de flecha, raspadores, raederas y una cuantas perlas de piedra para adornos. Posteriormente, a su vuelta a Perú en 1956, en mes de setiembre, encontró en la región de Arcata una serie de "abris" a una altura de $4600 \mathrm{~m}$ "allí apareció una gran cantidad de artefactos, también puntas de flechas, raspadores y raederas. El tipo de estos artefactos es el mismo que el de Ichuña. Según la tipología los artefactos corresponden al Ayanpitiense, una cultura del Epimiolítico americano, llamado según el pueblo de Ayanpitín en la provincia de Córdova" Schroeder, Revista del Museo Nacional, (57). En ningún momento presenta asociaciones con otros elementos (huesos, cenizas, pieles, etc.), no se si porque no los encontró, o porque no le interesaba. Es decir, no presenta contextos, sino que simplemente presenta las piezas y las describe, y no todas. Por otra parte, tampoco presenta estratigrafía, y la cronología de este yacimiento, solo con estas evidencias puede calcularse, estableciendo tipos bien definidos que por comparación con los de otros yacimientos cercanos ya fechados pueden darnos una edad relativa. Las piezas que tiene el Museo son 48 entre núcleos, raspadores, raederas, lascas y puntas. El mineral utilizado es generalmente obsidiana, pero también se utiliza cuarcita, hornstein, carneol, silex, etc. 


\section{Descripción:}

№ 1.- Núcleos: 2 (sin número "u” 2-1074)

\section{Raspadores:}

№ 2.- Raspador aquillado de cuarcita. Retocado solo en la parte terminal. En la parte ventral en la base, el bulbo está poco formado. Artefacto crudo ("u" 2-1074)

№ 3.- Raspador aquillado y pedunculado de hornstein con un ligero retoque dorsal en la parte basal posiblemente a presión. En la parte terminal lateral de la cara dorsal se ha hecho un retoque a percusión. En la parte basal de la cara dorsal forma una especie de pedúnculo. Es una forma atípica de esta cultura (ilustrada) (2.1074 "u").

№ 4.- Raspador aquillado redondo con retoque dorsal y circular de obsidiana (2-1074-"u") Fig. 13 a y b.

№ 5.- Raspador plano de cuarcita con retoque terminal en el lado dorsal y con retoques escarpeados en la base ("u" 2-1074)

№ 6.- Raspador plano de sílice con retoque terminal y lateral izquierdo en la cara dorsal ("u" 2-1074).

№ 7.- Raspador plano de hornstein con retoque escarpado en la parte terminal de la cara dorsal ("u" 2-1074)

№ 8.- Raspador plano de carneol con retoque escarpado circular, menos en la base ("u" 2-1074).

№ 9.- Raspador plano de hornstein con retoque escarpado circular, en la cara dorsal. Bulbo retocado ("u" 2-1074).

№ 10.- Raspador discoidal plano de obsidiana con retoque escarpado y circular ("u" 2.1073).

№ 11.-Raspador discoidal plano de obsidiana con retoque escarpado y circular. La parte terminal está quebrada ("u" 2.-1073).

№ 6. - (dib).- Pequeño raspador discoidal de obsidiana negra con retoque circular en la cara dorsal. El trabajo es muy delicado y el astillamiento muy fino ("u" 2-1073) Fig. 11.

\section{Raederas:}

№ 12.- Raedera quebrada de carneol. Retoque bifacial, e.d. en la cara ventral (abajo) y dorsal (arriba). Retoque de corte bien marcado en la parte lateral izquierda. ("u" 2-1072).

№ 13.-Raedera de cuarcita con retoque de corte en ambos lados ("u" 2-1074).

№ 14.- Raedera de pizarra silicificada con retoque escarpado en la parte lateral izquierda y retoque de corte en la parte lateral derecha.

№ 16.- Raedera plana de carneol oscuro con retoque de corte en ambos lados. ("u" 2.1074).

№ 17. - Raedera de obsidiana negra con retoque de corte en ambos lados.

№ 18. - Raspador y raedera de obsidiana negra, discoidal, típico, con retoque de raspador en la parte terminal y lateral derecha. Retoque de corte en la parte lateral izquierda ("u" 2-1074) Fig. 12 a y c.

\section{Lascas:}

№ 19.- Lasca quebrada de obsidiana negra. El resto es la parte terminal con retoque de corte en ambos lados. ("u" -2-1073).

№ 20.- Lasca de obsidiana negra con retoque bifacial. En las partes laterales tienen retoques de corte. Schroeder dice que pudo ser intencionalmente hecha como punta de flecha. Esto es seguro y el trabajo en la cara dorsal así lo indica. Esa cara tiene un retoque típico de punta de proyectil con un trabajo de astillado bastante grande facial y retoque de corte lateral en ambos lados. La cara ventral tiene la forma cóncava característica de las lascas de obsidiana sin bulbo y con un ligero trabajo de corte lateral ("u"2-1071). Atípica. Fig. 1 a, b y c.

№ 21.- Lasca delgada de cuarcita sin retoques ("u" 2-1075).

№ 22. - Lasca delgada de obsidiana con retoque facial en la cara dorsal ("u" 2-1075).

№ 23. - Lasca delgada de cuarcita con retoques de corte muy finos en la parte lateral derecha ("u" 2-1075).

№ 24.- Lasca de obsidiana con retoques finos de corte en ambos lados ("u" 2-1075).

№ 25. - Lasca delgada de obsidiana con retoque de corte en ambos lados. ("u" 2-1075).

№ 26. - Lasca delgada de obsidiana con retoque facial de la cara dorsal ("u" 2.-1075).

№ 27. - Lasca delgada de obsidiana con retoque facial dorsal ("u" 2-1075). 

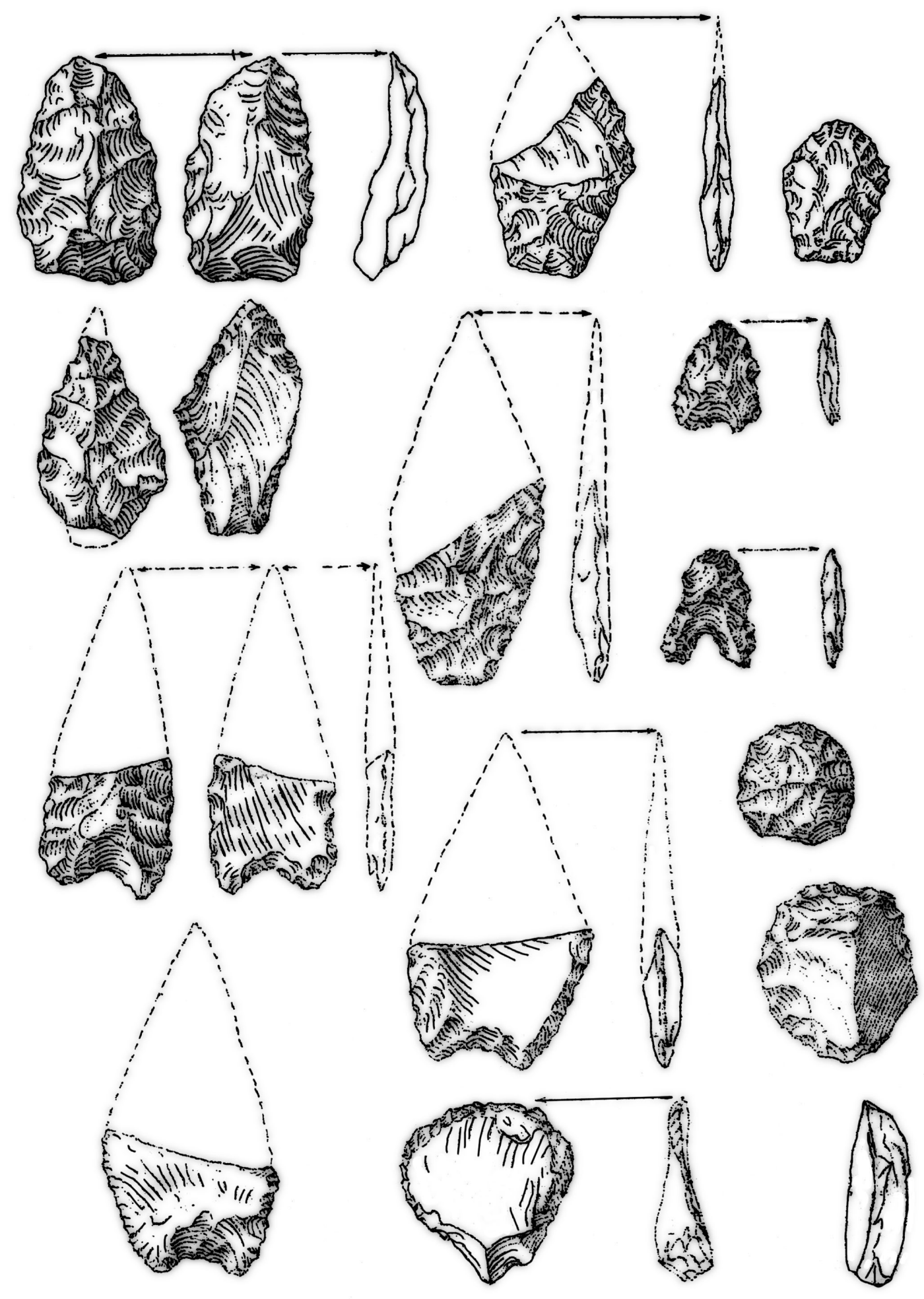
№ 28. - Lasca de obsidiana con retoque facial dorsal ("u" 2-1075).

№ 29.- Lasca fina de obsidiana sin retoques ("u" 2-1075).

№ 30.- Lasca delgada de obsidiana con retoque facial dorsal ("u" 2-1075).

№ 31. - Lasca fina de obsidiana sin retoques ("u" 2-1075).

№ E7 ("u” 2-1075) Lasca delgada de obsidiana negra con ligeras tonalidades rojas, finos retoques de corte en ambos lados de la cara dorsal y muy ligeros en la lateral derecha de la cara ventral.

SIN NÚMERO "u" 2-1075.- Lasca de obsidiana negra con ligeros retoques de corte en ambos lados de la cara ventral.

SIN NÚMERO "u" 2-1075.- Lasca de carneol delgada con ligerísimos retoques en ambos laterales de la cara dorsal y en el fin terminal.

\section{Puntas de proyectil:}

№ 32 Punta de lanza de carneol, con retoque de corte en ambos lados. Su forma es ligeramente pedunculada en forma de cincel. La parte terminal que da la punta es corta y redondeada, casi circular. Las formas pedunculadas en cincel se dan en otras piezas de Arcata, pero esta otra forma de terminal es más rara. Forma atípica. Fig. 3

№ 33.- Punta de cuarcita de forma romboidal con retoque facial solo en la cara dorsal. La cara ventral tiene, al igual que la dorsal, retoque de corte. La cara ventral es cóncava. En realidad, al igual que la № 20 ya citada, es una lasca trabajada como punta. Forma atípica de esta cultura. ("u" 2-1072).

№ 34.- Es en realidad otra lasca aprovechada para punta de flecha. Tanto en la cara dorsal como en la ventral la fractura de la lasca se conserva por no tener en ninguna marcado retoque facial. Tiene retoque de corte en ambos lados, su forma es ligeramente romboidal, con retoque en su base pedunculada en forma de cincel para colocar la punta. Parece ser esta la que el Dr. R. Ravines relacionándolas con las puntas romboidales de Caru ("u" 2-1075) Fig. 5.

№ 36.- Punta de cuarcita con retoque facial dorsal. En realidad es otra lasca aprovechada. Sus lados son aserrados. Su forma es ligeramente romboidal. La cara ventral no ha sido retocada, y tampoco retoques de cortes laterales en ninguna de sus caras. Atípica como la anterior ("u" 2-1075).

№ 37. - Punta de flecha de obsidiana quebrada. Tiene retoque bifacial muy fino, y su fin basal es pedunculado en forma de cincel. ("u" 2-1071). También atípica. Fig 2 a y b.

№ 38. - No la cita Ravines, pero creo que se asemeja a algunas puntas de Caru, así como las de Tarata y el nivel medio de Toquepala. Es decir, es negro. Tiene forma ligeramente romboidal. Su fin basal y su fin terminal están fracturados. Tiene ligeras aletas laterales como las arriba citadas. El retoque ha sido hecho a prisión, y también en el trabajo se asemeja a éstas. Los bordes son ligeramente aserrados. ("u" 2-1071). Fig. 4.

№ 40.- Punta de flecha de obsidiana con retoque bifacial y escotadura marcada en la base. El escote es curvo y aserrado. Es forma típica de esta cultura y se asemeja a las de nivel superior de Toquepala. ("u" 2-1071). Fig. 8 a y b.

№ 42.- Punta de obsidiana con retoque bifacial del mismo tipo que el anterior, pero menos pronunciada en la base. ("u" 2.-1071) Fig. 7 a $\mathrm{yb}$

№ 43. - Es una lasca de forma triangular utilizada de punta. Tiene retoque facial en la cara dorsal en forma cruda, y un ligero retoque de corte en el lateral derecho de la cara dorsal. El fin basal ha sido escotado en forma cruda. La punta es de obsidiana. ("u" 2-1075).

№ 11 (dib). - Punta de proyectil de cuarcita fracturada. Parte inferior de la misma. Retoque bifacial y retoque de corte en ambos lados; en la cara ventral ha sido trabajada suavemente a presión. Su forma es foliácea y, por tanto, atípica. ("u" 2-1072) Fig. 6 a y b.

№ 12 (dib).- Fragmento de la parte inferior de una punta de obsidiana negra con escote curvo y aserrado. Retoque bifacial muy bien trabajado y retoque de corte en ambos lados. ("u" 2-1071) Fig. 9 a, b y c.

№ 13 (dib).- Fragmento de la parte inferior de una punta con ligero escote curvo y aserrado. Retoque bifacial ligero, más pronunciado en la cara ventral y en la parte lateral derecha y basal de la cara dorsal. Trabajo realizado a percusión y presión ("u" 2-1072). Fig. 10 a, b y c.

№ 14 (dib).- Fragmento pequeño de la parte superior de una punta de obsidiana. Retoque 
bifacial y retoque de corte en ambos lados. La cara dorsal está mejor trabajada. El trabajo es muy fino. ("u" 2-1071).

Se puede observar tras esta ligera descripción, que contando con materiales de otros yacimientos de esta área, con los que ha podido haber relaciones, puede hacerse a un nivel superior, un trabajo profundo. Hay material más que suficiente para realizar un estudio estadístico, incluso para establecer curvas de popularidad.

El Dr. Schroeder dice que los materiales de Arcata corresponden, tipológicamente, al Ayampitiense II y cronológicamente estarían situados entre 6000 y 4000 años a. C. Creo que más importante que esto es, por el momento, limitar sus relaciones culturales al ámbito de Extremo Sur del Perú, para poder hacer un estudio en profundidad por áreas. El Dr. R. Ravines, en un artículo publicado en el № 5 de Nawpa-Pacha, Berkeley, 1967, con el título de "El abrigo Caru y sus relaciones culturales con otros sitios tempranos del Sur del Perú”, establece una serie de relaciones entre distintos yacimientos del sur peruano en un área muy definida. El estudio de las relaciones culturales ocupa la parte final de su artículo, y, en realidad, no es sino una pequeña relación, pero de apunte es interesante. Ravines toma como principales puntos de referencia para establecer relaciones por una parte Caru (PTa2-5) y por otra parte el nivel medio del abrigo № 2 de Toquepala (PTal-2). Este abrigo de Toquepala es interesante porque en él es evidente una evolución en piezas líticas, sobre todo puntas. Su nivel superior está caracterizado por pequeñas puntas triangulares y escotadas en la base. Este tipo de punta es típico en Arcata. En el nivel medio de Toquepala hay puntas foliáceas pedunculadas, de bordes finamente dentados que también se dan en Arcata. Se da un ejem- plar con ligeras aletas laterales, de silex negro, como en Caru, su pedúnculo no puede verse porque está fracturado. Este es el tipo de punta que Ravines encuentra en Caru y llama romboidales con aletas laterales. Igualmente se dan en el nivel 2 de Tarata qye según Ravines "parecen ser derivaciones posteriores de las puntas pedunculadas aserradas del nivel medio de Toquepala" (Nawpa Pacha, 1967, p.48). Por otra parte, con respecto a las posibles relaciones entre Arcata y Caru, dice Ravines que en Arcata hay "una punta de proyectil de obsidiana de forma romboidal. Retocada muy ligeramente a presión, que es muy semejante en su forma y detalle de fractura a las puntas del abrigo Caru" (Ravines, Nawpa Pacha, 1967, p.51). Vistas estas relaciones podemos, en cierta forma, aventurar una cronología relativa para Arcata. Las puntas pedunculadas y romboidales relacionadas con Caru y el nivel medio de Toquepala serían las más antiguas y estarían, como dedujo Schroeder por el fechado de los estratos geológicos de Ayampitín, entre los 6000 y 4000 años a. C. Las puntas escotadas típicas son posteriores, y se relacionan con el nivel superior de Toquepala con una antigüedad de unos 2000 años a. C.

El esbozo de un estudio sistemático de la zona ya está trazado, aunque, por supuesto, faltan muchos elementos y los yacimiento son también más de los aquí citados, por lo que las posibilidades se multiplican (Playa Chira I, Pampa Colorada, Quebrada de los Perros, Catarindo, Ichuña).

$\mathrm{Su}$ importancia es enorme, sobre todo ahora cuando la arqueología en el Perú se va abriendo paso al definitivo y casi familiar Pleistoceno, de acuerdo a los recientes descubrimientos conocidos. 